\title{
Negociar en red: familia, amistad y paisanaje. El virrey Superunda y sus agentes en Lima y Cádiz (1745-1761)*
}

Pilar Latasa

Universidad de Navarra

Este artículo pretende dar una nueva perspectiva del gobierno peruano del virrey conde de Superunda, a través de un primer acercamiento a su red clientelar privada. Se trazan, en primer lugar, sus conexiones en la corte madrileña, para llegar después a las relaciones de parentesco y paisanaje que le unen con sus familiares y criados más cercanos en la corte virreinal limeña. Todo ello conduce a vislumbrar qué tipo de vínculos mantuvo con quienes fueron sus agentes en cuestiones económicas durante su estancia en el virreinato; a través de los cuales envió importantes sumas de dinero a la península, como se demuestra por la documentación. Este análisis permite descubrir un amplio entramado que unió lugares tan distantes como Lima, Cádiz, Madrid y La Rioja y se mantuvo incluso tras el regreso de Superunda a España.

Palabras clave: José Manso de Velasco, conde de Superunda, virrey del Perú, virreinato del Perú (1745-1761), redes sociales, redes económicas, redes clientelares, parentesco, paisanaje, Lima, Cádiz, La Rioja.

In order to reassess the Peruvian government of Viceroy conde de Superunda, this article represents a first approach to his private client networks. Staking out his connections in Royal Madrid's Court, discussion focuses on describing the relations of kinship and nationhood which unite him with his family members and closest servants in the Viceroyal Court of Lima. The former depicts an overall picture of the kind of relationship he maintained with his agents in economic issues during his stay in the viceroyalty. Through this analysis a wide framework uniting distant places such as Lima and Cádiz, Madrid and La Rioja —connections maintained ever after Superunda's return to Spain-is outlined.

KeYwords: José Manso de Velasco, conde de Superunda, Viceroy of Peru, Viceroyalty of Peru (17451761), social networks, economic networks, client networks, kinship, nationhood, Lima, Cádiz, La Rioja.

Desde los primeros estudios prosopográficos de la administración hispana en América, publicados en los años setenta, el interés por profundizar en el estudio de los burócratas indianos ha sido creciente. La facilidad para definir grupos dentro de la administración colonial de la América españo-

* Este trabajo se enmarca dentro del Proyecto Coordinado de Investigación Científica y Desarrollo Tecnológico titulado: Relaciones entre el Perú y España, siglos XVIII-XX. El trasfondo de la política oficial en las redes familiares, sociales, económicas e institucionales, BHA 2000-1224-C02-01, cuyo investigador principal es Alfredo Moreno Cebrián. 
la, junto con la abundancia de fuentes disponibles, ha permitido aplicar la prosopografía con éxito para dar un nuevo enfoque y avanzar hacia inexploradas líneas de investigación dentro de la historia político-administrativa. Se trata de conocer el modo en que se articularon las relaciones en el ámbito privado de estos burócratas con el fin de calibrar mejor, con una perspectiva más amplia, la incidencia de factores de tipo personal en el acceso y en el ejercicio de tareas administrativas. ${ }^{1}$

El período de gobierno del virrey José Manso de Velasco, conde de Superunda (1745-1761) cuenta ya con destacados estudios monográficos ${ }^{2}$ y recientes artículos a los que se hará referencia más adelante. Sin embargo, este trabajo pretende dar una distinta visión de la figura de este virrey en un primer acercamiento a su red clientelar. Un entramado que empieza con su círculo de influencias en la corte madrileña, continúa con las relaciones de parentesco y paisanaje que le unen a sus familiares y criados más cercanos y conduce a vislumbrar quiénes fueron sus agentes en cuestiones económicas. ${ }^{3}$

1 No es éste lugar para hacer una valoración historiográfica, me remito a una reciente revisión de los estudios en torno a grupos sociales en el virreinato peruano - conquistadores, encomenderos, agentes de la administración, comerciantes, miembros de las capas altas y sectores populares- de Puente Brunke, José de la: "Grupos sociales y biografía colectiva en la historia del virreinato de Perú: una aproximación”, Memoria y civilización, 5, Pamplona, 2002, págs. 119-151. Otro trabajo reciente es el de Latasa Vassallo, Pilar: "Comerciantes, burócratas y aristócratas en la Lima borbónica: revisión historiográfica", Pilar Latasa (coord.): Reformismo y sociedad en la América borbónica. In memoriam Ronald Escobedo, Universidad de Navarra, Eunsa, Pamplona, 2003, págs. 227-252.

2 Un trabajo de obligada referencia para el gobierno de este virrey es el de Moreno Cebrián, Alfredo (edición y estudio): Relación y documentos de gobierno del virrey del Perú, José A. Manso de Velasco, Conde de Superunda (1745-1761), Instituto Gonzalo Fernández de Oviedo, Madrid, 1983. Recientemente se ha publicado también la obra de Pérez-Mallaina Bueno, Pablo Emilio: Retrato de una ciudad en crisis: la sociedad limeña ante el movimiento sísmico de 1746, Escuela de Estudios Hispanoamericanos, Sevilla, 2001, en la que el terremoto de 1746 es aprovechado para describir las tensiones sociales y los mecanismos de poder existentes en la ciudad en ese momento. Muy sugerente es también el trabajo de Walker, Charles F.: "The Upper Classes and Their Upper Stories: Architecture and the Aftermath of the Lima Earthquake", Hispanic American Historical Review, 83/1, Duke, NC., 2003, págs. 53-82.

3 Para la elaboración de este artículo se ha utilizado, entre otras, la documentación del Fondo Samaniego, que se conservaba en el Palacio del mismo nombre situado en La Guardia (Álava). Allí la consultó Diego Ochagavía Fernández, para hacer la primera biografía del virrey: "El I Conde de Superunda", Berceo. Boletín del Instituto de Estudios Riojanos, Logroño, año 16, n 58, 1961, págs. 5-48; año 16, nº 59, 1961, págs.161-176; año 16, nº 60, 1961, págs. 321-332; año 16, nº 61, 1961, págs. 7-24; año 17, n. 63, 1962, págs. 171-172. El Fondo, que integra la documentación de siete familias emparentadas, fue posteriormente vendido a la Diputación Foral de Álava. Actualmente se encuentra en el Archivo del Territorio Histórico de Álava, en Vitoria. Existe un primer inventario del mismo publicado por, Urdiáin Martínez, Camino: Archivo provincial de Álava. Fondo Samaniego. Inventario de documentos, Diputación Foral de Álava, Vitoria, 1984. El primer análisis, desde un punto de vista americanista, de esta documentación es el estudio de Martínez de Salinas Alonso, Ma Luisa: "Noticias del virrey conde de Superunda en el Archivo de la Diputación Foral de Álava”, Ronald Escobedo Mansilla, et al.: Álava y América, Diputación Foral de Alava, Vitoria-Gasteiz, 1996, págs. 351-364. 


\section{Un hombre de Ensenada}

José Antonio Manso de Velasco había nacido en 1689 en Torrecilla de Cameros. ${ }^{4}$ Era el segundón, tras su hermano Diego, de una familia media poseedora de una cabaña ganadera y de un pequeño lavadero de lanas a orillas del río Iregua. ${ }^{5}$ Sin ser privilegiada, parece que su situación económica era acomodada en comparación con la de otros propietarios de ganado ovino de la montaña camerana. Sin embargo, como los datos que permiten calibrar con mayor fiabilidad el nivel económico de los Manso de Velasco son posteriores a la primera mitad del XVIII, es fácil distorsionar la realidad anterior. Es precisamente a partir de 1748 cuando tenemos constancia de que Diego - hermano del entonces ya virrey del Perú-, solicita ampliar el lavadero existente. A partir de ahí, Angulo Morales demuestra la bonanza que experimentó el negocio familiar hasta su estancamiento, a finales del último tercio del siglo, y su liquidación en 1821, por parte de Mariano Antonio Manso de Velasco, nieto de Diego Manso de Velasco. ${ }^{6}$

Razones geográficas impulsaron el desarrollo de la ganadería ovina de carácter trashumante en la Sierra de Cameros, que hacía precisa la vinculación de los pequeños propietarios de la zona con grandes terratenientes, principalmente de Extremadura. Por otro lado, la calidad de la lana merina y la seguridad de precios moderados atrajeron el interés de casas comerciales francesas, sobre todo de Bayona, por el mercado de las lanas castellanas. En el caso de los Manso de Velasco, entre 1737 y 1794 la producción de esta cabaña lanar y la administración del lavadero estuvo en manos de negociantes bayoneses. No son datos aleatorios: ambas relaciones

4 Localidad actualmente situada en la comarca de Camero Nuevo, en La Rioja. Sus padres, Diego Sáenz Manso de Velasco y Ambrosia María Sánchez Samaniego, eran también riojanos, oriundos de Torrecilla y La Guardia respectivamente.

5 El lavadero, único ingreso del señorío de Superunda, producía unos ingresos anuales de 3.000 reales. Véase Ibañez Rodríguez, Santiago, et al.: Los señoríos en La Rioja en el siglo XVIII, Universidad de La Rioja Servicio de Publicaciones, Logroño, 1996, pág. 132.

6 En 1751 el catastro de Ensenada daba una cifra de 13.000 cabezas para la cabaña de los Manso de Velasco, se puede considerar que tenía un tamaño intermedio. Angulo Morales, Alberto: "Comercio y financiación del negocio lanero de los Manso de Velasco (1790-1840)", Rafael Torres Sánchez (ed.): Capitalismo mercantil en la España del siglo XVIII, Eunsa, Pamplona, 2000, págs. 249251. Véanse también Angulo Morales, Alberto: "La Real Compañía Ganadera de Soria y Burgos. El negocio lanero a finales del siglo XVIII", Agustín González Enciso (ed.): El negocio de la lana en España (1650-1830), Eunsa, Pamplona, 2001, págs. 269-310 y Herrero Hernández, Ma Ángeles: "La decadencia de la ganadería trashumante en la Sierra de Cameros (1780-1821)", Revista de Historia Económica, 10/2, Madrid, 1992, págs. 201-212. 
comerciales — condicionadas por el negocio de la lana-, estarán presentes, como veremos, en los "negocios" del virrey Manso de Velasco.?

En cualquier caso, a pesar de esta digresión, la lana y sus beneficios recayeron en Diego, el primogénito, y José Antonio optó por la carrera militar. En 1705 ingresó en el regimiento de Reales Guardias Españolas —un cuerpo de elite $-{ }^{8} \mathrm{y}$, tras una brillante carrera de ascensos durante la Guerra de Sucesión, pasó a la campaña de Orán y después a las de Italia, cuando la política exterior de Felipe V se encaminó hacia la recuperación de los territorios italianos. ${ }^{9}$

Así, en 1736 - fecha en que será nombrado gobernador, capitán general y presidente de la Audiencia de Chile- acumulaba un historial de treinta y un años al servicio de la monarquía borbónica en los ejércitos reales; era ya capitán de granaderos del regimiento de guardias de infantería española, brigadier de los reales ejércitos y caballero de la orden de Santiago. Pertenecía, por lo tanto, a esa generación de hombres que lucharon en la Guerra de Sucesión y después, como militares prestigiosos, ocuparon puestos destacados en la administración hispana tanto en Europa como en América. Además, José Manso de Velasco había tenido oportunidad de

7 Angulo Morales: “Comercio y financiación del negocio lanero”, págs. 256-274.

8 Estaban compuestas por dos unidades de caballería, Guardias de Corps y Carabineros Reales, y tres de infantería, los Alabarderos y dos regimientos de Reales Guardias Españolas de Infantería. Eran unidades que debían estar siempre en la vanguardia de las contiendas. Sus oficiales percibían sueldos más altos que los de los otros cuerpos y poseían mayor graduación al ser transferidos a otros regimientos. Véanse Andújar Castillo, Francisco: Los militares en la España del siglo XVIII. Un estudio social, Servicio de Publicaciones de la Universidad, Granada, 1991; Andújar Castillo, Francisco: "La educación de los militares en la España del siglo XVIII", Chronica Nova, 19, Granada, 1991 y Ozanam, Didier: "La política exterior de España en tiempo de Felipe V y de Fernando VI", José $\mathrm{M}^{\mathrm{a}}$ Jover Zamora (dir.): La época de los primeros Borbones, la nueva monarquía y su posición en Europa (1700-1759). Historia de España Menéndez Pidal, XXIX;1, Espasa Calpe, Madrid, 1985.

9 Archivo General de Indias de Sevilla (en adelante AGI), Contratación, 5.483, N. 2, R. 2, f. 1-15v. "Expediente de información y licencia de pasajero a Indias de José Manso, Presidente de la Real Audiencia de Santiago de Chile". Cádiz, 29 de diciembre de 1736. Copia en, ATHA, F. Samaniego, Caja 39, N. 37. José Antonio Manso de Velasco había destacado en la Guerra de Sucesión: en el sitio de Alcántara (1706) —en el que fue herido — en el de Tortosa (1708), en la batalla de Gudiña (1709), en la de Estadilla (1710), en el socorro de Ainsa y cañoneo de Balaguer, así como en los encuentros de Peñalva y Almenara, batallas de Zaragoza y Villaviciosa. Continuó participando en las campañas que tuvieron lugar entre 1711 y 1714, fecha en que estuvo en el bloqueo y sitio de Barcelona. Posteriormente formó parte de las expediciones a Cerdeña (1717) y a Ceuta, así como en el embarco de las tropas destinadas al sitio de Gibraltar; pasó después a la expedición de Orán. Más tarde participó en las campañas de Italia, donde estuvo en el sitio de Gaeta — Reino de Nápoles_-, en el de Sicilia, y en el sitio de Castel Lamer - Palermo - desde donde entró a la campaña de Lombardía. Estos datos se confirman en la "Satisfacción de los cargos del fiscal de la Superior Junta de Guerra, formada por orden de S. M. para conocer de la defensa y rendición de la ciudad de La Habana", Madrid, 28 de abril de 1764, citado por Moreno Cebrián: Relación y documentos de gobierno del virrey del Perú, pág. 17, actualmente en el Archivo del Territorio Histórico de Álava, (en adelante ATHA), F. Samaniego, Caja 40, N. 19. 
conocer de cerca y trabar amistad, en Orán e Italia, con su paisano Zenón de Somodevilla y Bengoechea, que ese mismo año recibió el título de marqués de la Ensenada. ${ }^{10}$

En 1736 Ensenada era ya un personaje destacado de la corte madrileña, que había prestado dilatados servicios dentro de la Secretaría de Marina durante casi veinte años. Desde entonces había ido estableciendo una amplia red de clientela en puestos claves dentro y fuera de la corte. ${ }^{11}$ Con ello, al tiempo que promocionaba a amigos y paisanos, introducía a personas capaces de acometer su plan de reformas: hombres en su mayoría plebeyos, como él mismo, pero cualificados y leales. ${ }^{12}$ Es, por lo tanto, más que probable que el nombramiento de José Antonio Manso de Velasco como gobernador de Chile, se debiera a la influencia del que en 1743 ocuparía las secretarías de Hacienda, Guerra, Marina e Indias. De hecho, tanto el cántabro, Juan Francisco de Güemes y Horcasitas, ${ }^{13}$ virrey de México entre 1746 y 1755, como el navarro, Sebastián de Eslava, ${ }^{14}$ virrey de Nueva Granada entre 1749 y 1759 , eran también militares curtidos en la Guerra de Sucesión, de extracción social hidalga y norteña y, sobre todo, protegidos de Ensenada, con quien habían coincidido igualmente en Orán e Italia. Por

10 El marqués de la Ensenada había nacido en Hervías en 1702, aunque toda su familia conservó la naturaleza de Alesanco, otro término de La Rioja, colindante por el norte. Tras la muerte de su padre, la familia se trasladó a vivir a Santo Domingo de la Calzada. Aunque desde los 18 años Zenón emigró a Cádiz en busca de trabajo, mantuvo siempre fuertes los lazos que le unían con su tierra natal. La biografía más completa existente hasta el momento es la de Abad León, Felipe: El marqués de la Ensenada, su vida y su obra, Editorial Naval, Madrid, 1985, 2 vols.

11 Sobre estas alianzas existe un trabajo de González Caizán, Cristina: "El primer círculo de hechuras zenonicias”, José Miguel Delgado Barrado y José Luis Gómez Urdáñez (coords.): Ministros de Fernado VI, Servicio de Publicaciones de la Universidad de Córdoba, Córdoba, 2002, págs. 177-202. El gran poder adquirido así por Ensenada provocaría el recelo del duque de Huéscar, principal artífice de su caída en 1754. Véase Gómez Urdañez, José Luis: "El duque de Duras y el fin del ministerio Ensenada (1752-1754)", Hispania, 59/1, Madrid, 1999, págs. 217-249.

12 Para el reformismo americano de Ensenada véanse Mijares, Lucio: "Programa político para América del marqués de la Ensenada”, Revista de Historia de América, 81, México 1976, págs. 82-130 y Navarro García, Luis: "La política indiana", Historia General de España y América, XI/1: América en el siglo XVIII. Los primeros Borbones, Rialp, Madrid, 1983, págs. 3-64.

13 Valle Menéndez, Antonio del.: Juan Francisco de Güemes y Horcasitas: primer Conde de Revillagigedo, Virrey de Mexico. La historia de un soldado (1681-1766), Ediciones Librería Estudio, Santander, 1998.

14 Nacido en 1685, en Enériz (Navarra), Sebastián Carlos de Eslava Lasaga fue el cuarto hijo varón del matrimonio formado por Gaspar de Eslava y Berrío y Rafaela de Lasaga y Eguiarreta. Eslava, después de una larga carrera militar, fue nombrado en 1739 virrey, capitán general y presidente de la audiencia del virreinato de Nueva Granada. Su carrera militar y conexión con Ensenada ha sido estudiada por Vázquez Varela, Ainara: Estrategias familiares en Navarra y América durante la Edad Moderna: la familia Eslava-Lasaga, un linaje de funcionarios y militares, trabajo de investigación inédito, Departamento de Historia, Universidad de Navarra, 2003; actualmente prepara su tesis doctoral sobre El restablecimiento del virreinato de Nueva Granada: gobierno de Sebastián de Eslava (1739-1749). 
lo tanto, durante la década de los cincuenta (1749-1759) los tres virreinatos americanos estuvieron ocupados por hombres de Ensenada. ${ }^{15}$

La correspondencia personal entre Manso y Ensenada confirma esta estrecha relación. El virrey se dirige en una carta al ministro en estos términos:

"Persona del alma: pocas son las ocasiones que nos ofrece el tiempo para expresar con la pluma la continua memoria de lo que siente y desea un verdadero amor: como este se asegure en la perfecta salud de vuesa merced, no le quedo que apetecer". ${ }^{16}$

\section{Deudas del viaje a Chile}

Pero volvamos a Cádiz, a finales de 1736, donde José Antonio Manso de Velasco se preparaba para embarcar hacia América en el primer barco. Debía pasar a Chile lo más rápido posible porque el anterior gobernador, Bruno Mauricio de Zabala, había fallecido. El nombramiento se había cursado de hecho con celeridad. Convenía además designar persona "de toda confianza servicios, valor y experiencias militares" que desempeñara el cargo "con la integridad, celo y cuidado que se requiere". Felipe V consideró que todas estas circunstancias concurrían en José Antonio Manso de Velasco y, probablemente, Ensenada se lo corroboró.

Este cargo era retribuido con una salario anual de 8.000 pesos de a ocho (85.000 reales de vellón). ${ }^{17}$ Probablemente era el sueldo más alto percibido hasta entonces por el capitán de granaderos, pues algunos datos revelan su poco saneada economía antes de partir hacia el Chile. ${ }^{18}$

15 Abad León: El Marqués de la Ensenada, I, págs. 349-354, se refiere a la admiración de Ensenada por "sus" virreyes puesta de manifiesto en una representación hecha por el secretario al rey en 1747: "Hay en las Américas los tres virreyes, Eslava, Manso y Horcasitas, que no se pueden mejorar".

16 AGI, Lima, 642. Carta de José Manso de Velasco al marqués de la Ensenada. Lima, 12 de agosto de 1746. Dentro de una carpeta pequeña en la que se lee: "Cartas reservadas del virrey Manso al señor marqués de la Ensenada, en año de 1746". Menciona esta correspondencia privada PérezMallaina Bueno: Retrato de una ciudad en crisis, pág. 105.

17 En este trabajo todas las cantidades se transformarán en reales de vellón siguiendo las tablas de Rendón Fuentes, Francisco: Prontuario aritmético y reducción de unas monedas a otras, Cádiz, 1763.

18 ATHA, F. Samaniego, Caja 39, N. 37. Incluye los siguientes documentos: "Título de Presidente de la Real Audiencia de Santiago de Chile dado por Felipe V en la persona de José Manso", San Ildefonso, 18 de octubre de 1736; "Título de Gobernador y Capitán General del Reyno de Chile dado por Felipe V en la persona de José Manso", San Ildefonso, 18 de octubre de 1736; “Testimonio de Juramento tomado a D. Joséph Manso por D. Antonio de Salazar y Castillo, secretario de S. M. 
Por ejemplo, a pesar de la autorización de viajar con un máximo de ocho criados, Manso de Velasco llevó tan sólo uno, Diego de Hesles Campero, de quien se hablará más adelante. ${ }^{19}$ El brigadier tenía además licencia para viajar con su equipaje y mil onzas en plata labrada, todo ello exento de impuestos. El funcionario que tomó nota de los bultos que se cargaron a su nombre en el navío El Conquistador, que partió de Cádiz en enero de 1737, detallaba que eran un total de diecisiete baúles. Doce de ellos estaban llenos de "ropa blanca y de color" — de uso personal para él y sus criados - en los que iban también: cuatro veneras guarnecidas de diamantes, rubíes y esmeraldas, dos pares de botones para camisa de diamantes, dos "piezas de olanda" y dos "medias piezas de olanda de baptista". En cuanto a los otros cinco cajones: uno guardaba dos sillas de caballo, otro iba lleno de vasos de cristal, otro de libros "de su uso", frasqueras de licores y "trastos de cocina"; finalmente, dos baúles contenían 150 libras de "tavaco lavado de chupar", guardados a su vez en 53 botes de lata, destinados — según se hacía constar - a su consumo personal. Al margen, el funcionario anotaba que llevaba también las mil onzas de plata labrada autorizadas por la corona, es decir, casi $30 \mathrm{kgs}$. de este metal. ${ }^{20}$

Las joyas y telas descritas eran probablemente un regalo del "jefe", como habitualmente Manso se refería a Ensenada. Respondían a la necesidad de ostentación de su nuevo status. Los lienzos finos europeos, muy utilizados para la confección de camisas y sábanas, eran muy cotizados en América. Las veneras serían un permanente distintivo de su condición de caballero de Santiago. Pero, sin duda, lo más llamativo son los dos cajones de tabaco, para los que llevaba una autorización especial de la Junta de Renta General del Tabaco, por la que se le permitía llevar a Chile las mencionadas 150 libras, alrededor de $60 \mathrm{kgs}$., compradas por el propio Manso en las Reales Fábricas de Sevilla. ${ }^{21}$ El valor del cargamento era de 8.470 y

y escribano de cámara del Consejo de Indias", Madrid, 16 de noviembre de 1736. ATHA, F. Samaniego, Caja 40, N. 09. Pasaporte dado por Casimiro de Uztáriz, secretario de la real junta de comercio y moneda y oficial mayor de la secretaría del despacho de guerra, a D. Joséph Manso de Velasco, gobernador y capitán general del reino de Chile, que con sus criados y equipaje pasa de este real sitio a la plaza de Cádiz. San Lorenzo de El Escorial, 13 de noviembre de 1736.

19 AGI, Contratación 5.483, N. 2, R. 2, f. 11-15v. "Expediente de información y licencia de pasajero a Indias de José Manso, Presidente de la Real Audiencia de Santiago de Chile”. Cádiz, 29 de diciembre de 1736 .

20 ATHA, F. Samaniego, Caja 40, N. 09. Decreto para que no se ponga impedimento alguno al equipaje que lleva consigo Joséph Manso, próximo a hacer viaje a Tierra Firme. Cádiz, 4 de enero de 1737.

21 ATHA, F. Samaniego, Caja 40, N. 09. Licencia dada a Joséph Manso para llevar 150 libras de tabaco de chupar a Chile. Madrid, 18 de noviembre de 1736. 
5 cuartos de reales de vellón y su venta estaba asegurada puesto que el estanco todavía no se había implantado en el virreinato. ${ }^{22} \mathrm{~A}$ ello se añaden los doce cajones de ropa, algo desproporcionado para dos personas. Parece evidente que en ambos casos se trata de comercio encubierto. Ni Manso de Velasco iba a consumir semejante cantidad de tabaco, ni los doce baúles de ropa eran para su uso personal; probablemente algunos cajones contenían telas y ropa sin estrenar. En resumen, ambas partidas contenían mercancías que le reportarían al capitán de granaderos ciertos beneficios que le permitirían hacer frente a un viaje tan costoso. La exención de impuestos en estos casos no suponía mucho a la corona y aliviaba en cambio las arcas del interesado. ${ }^{23}$

Sin embargo, estas facilidades no impedían que, de entrada, el viaje supusiera un fuerte desembolso. Es aquí precisamente donde la mala situación económica de José Manso de Velasco sale a relucir. La documentación demuestra que el recién nombrado gobernador pidió prestados casi 15.000 pesos de a ocho para afrontar el viaje (en concreto 14.659 pesos y 43 cuartillos o 220.746 y 43 cuartos de reales de vellón). ${ }^{24}$ El desglose sería el siguiente: una partida de 8.000 pesos antes de salir de Cádiz —el equivalente a un año de su sueldo-, otra partida de 6.659 pesos y 43 cuartillos reales para gastos de viaje, de los cuales 4.131 pesos y 43 cuartillos reales se le dieron antes de salir, dos partidas de 448 y 80 pesos que le fueron libradas por Nicolás de Berroa, hermano del anterior, a su llegada a

22 Agradezco las orientaciones para calcular el precio de este tabaco a Rafael Escobedo Romero que actualmente realiza su tesis doctoral sobre El monopolio fiscal del tabaco en España durante el siglo XVIII, Departamento de Historia, Universidad de Navarra. Precisamente sería José Manso de Velasco quien implantara el estanco de tabaco en Chile en 1753, siendo virrey del Perú. Véase, Moreno Cebrián: Relación y documentos de gobierno del virrey del Perú, págs. 97-99. Sobre el estanco de tabaco en el virreinato están los trabajos de Céspedes del Castillo, Guillermo: "La renta del tabaco en el virreinato del Perú”, Revista Histórica, XXI, Lima, 1954, págs. 138-163 y Fisher, John: "El estanco de tabaco en el Perú borbónico", Agustín González Enciso y Rafael Torres Sánchez (eds.): Tabaco y economía en el siglo XVIII, Eunsa, Pamplona, 1999, págs. 35-54. Para Chile véase el de Stapff, Agnes: "La renta del tabaco en el Chile de la época virreinal", Anuario de Estudios Americanos, 18, Sevilla, 1961, págs. 1-63.

23 Las licencias concedidas por la corona a determinadas personas para navegar a Indias sin pagar derechos aduaneros agravaron el fraude fiscal del siglo XVIII, García-Baquero Gonzalez, Antonio: Cádiz y el Atlántico (1717-1778). El comercio colonial español bajo el monopolio gaditano, Escuela de Estudios Hispanoamericanos, Sevilla, 1976, I, pág. 219.

24 Juan García Romero aparece matriculado en Cádiz en 1730. No hemos podido conseguir más datos de él pero el hecho de que años más tarde, en 1749, se matricule un Santiago García Romero Mayoral, originario de Sotes, en La Rioja, puede ser un indicio de que Juan era también riojano, pues tal vez se trate de un sobrino. Ruiz Rivera, Julián Bautista: El Consulado de Cádiz: matrícula de comerciantes, 1730-1823, Diputación Provincial, Cádiz, 1988, págs. 81, 118 y 322. 
Cartagena de Indias en marzo de $1737^{25}$ y 2.000 pesos le fueron entregados en Panamá por libranza de este último. ${ }^{26}$

Estos préstamos fueron hechos en 1737, con el compromiso de que José Antonio Manso de Velasco pagaría la deuda lo antes posible. Cabe preguntarse cómo pensaba hacerlo. Es fácil de suponer que el capitán de granaderos hubiera oído hablar de lo relativamente fácil que resultaba enriquecerse en América en el ejercicio de cargos oficiales. Sin embargo, parece que las cosas no fueron tan fáciles. En 1742 su hermano, Diego Manso de Velasco, residente en Torrecilla de Cameros, se vio obligado a recurrir al rey, acosado por Juan García Romero que quería cobrar las deudas de su hermano. Es decir, José Antonio no había devuelto todavía esos préstamos, a pesar de que llevaba ya cinco años en Chile. Diego, para calmar los ánimos del comerciante, y alegando que le resultaba imposible pagar esa cantidad "por la estrechez en que se hallaba", se comprometió a entregarle, desde junio de 1741, un interés del 6\%, "a estilo de comercio" - a pesar de que el préstamo se hizo inicialmente sin intereses-, hasta que su hermano cumpliera. Pero el comerciante gaditano procedió pronto a demandar legalmente el pago de la deuda. En su carta al rey, Diego Manso de Velasco reiteraba que no podía satisfacerla "sin la notable ruina que se deja conocer en perjuicio de su familia por no tener más bienes que una porción de cabaña real". Además aducía haber tenido noticia del pago del préstamo por una carta reciente de José Antonio, fechada en 1 de octubre de 1741. Por todo ello, y en atención a los distinguidos servicios de su hermano, entonces ya mariscal de campo, solicitaba al monarca que anulara cualquier acción legal emprendida contra él para el cobro de este crédito. ${ }^{27}$

A pesar de lo expuesto en esta carta, todo parece indicar que José Antonio no se preocupó de la deuda hasta que recibió estas noticias de su hermano. Fue entonces, en marzo de 1742, cuando consiguió que otros dos comerciantes gaditanos que tenían intereses en Chile, José de Guisasola y Pedro de Arriaga, le prestaran 8.000 pesos de a ocho, que fueron devueltos

25 ATHA, F. Samaniego, Caja 39, N. 01. Traslado hecho por Santiago de Santibañez, escribano público, a pedimento de D. Diego Hesles Campero, secretario del Excmo. Sr. D. Joséph Manso de una libranza dada en Cádiz en 15 de enero del año de 1737 por Juan García Romero, residente en esta ciudad, contra D. Nicolás de Berroa. Santiago de Chile, 16 de noviembre de 1744. La libranza auténtica está en ATHA, F. Samaniego, Caja 40, N. 10. Libranza de Juan García Romero, vecino de Cádiz a favor de José Manso para cobrar en Cartagena. Cádiz, 15 de enero de 1737.

26 ATHA, F. Samaniego, Caja 40, N. 10. Recibo firmado por José Manso por el que consta que ha recibido, de Nicolás de Berroa, 448 pesos. Cartagena, 14 de marzo de 1737.

27 ATHA, F. Samaniego, Caja 39, N. 01. Carta de Diego Manso de Velasco al rey. Torrecilla en Cameros, 1742. 
a Juan García Romero a través de su socio en Cádiz, el también comerciante Carlos de Ondona. ${ }^{28}$ El flamante gobernador y mariscal de campo cubrió así parte de la deuda con un nuevo préstamo que, por cierto, pagó tan sólo un año después siendo todavía gobernador de Chile. ${ }^{29}$ Pero quedaba pendiente de pago la otra cantidad, las deudas contraídas durante el viaje. En este caso los 6.559 pesos y 43 cuartillos de reales fueron enviados por el gobernador desde Chile a Nicolás de Berroa, a través de Matheo de la Torre y Juan Bautista de Mier y la Torre, comerciantes chilenos. Nicolás de Berroa recibió esa cantidad en Cartagena de Indias en abril de 1744 y Diego de Hesles, criado del gobernador, se apresuró a solicitar traslado notarial de toda la documentación en noviembre de ese mismo año. ${ }^{30}$

No deja de llamar la atención que tan sólo siete meses antes de partir hacia su nuevo destino en el virreinato peruano - oficialmente concedido en 24 de diciembre de 1744-, del que probablemente habría tenido noticias antes por sus contactos en la corte, Manso de Velasco dejara saldadas todas sus deudas. ¿Cómo lo consiguió? Hace años que Diego Barros Arana apuntara las múltiples acusaciones de fraude que se le hicieron como juez de residencia de sus antecesores: Gabriel Cano de Aponte y Manuel de Salamanca; sin embargo esta hipótesis no ha sido todavía demostrada. ${ }^{31}$

\section{Los criados más cercanos del virrey}

José Antonio Manso de Velasco arribó al puerto del Callao el 10 de julio de 1745. El poderoso Ensenada le daba la bienvenida en una carta en la que reconocía haberle elegido personalmente al tiempo que le confirmaba su apoyo:

28 José de Guisasola y Pedro de Arriaga aparecen ambos matriculados en Cádiz en 1732. Carlos de Ondona en 1734. Ruiz Rivera: El Consulado de Cádiz, págs. 119, 114, 122.

29 ATHA, F. Samaniego, Caja 39, N. 01. Declaración de Guisasola y Arriaga de haber recibido 8.000 pesos de Joséph Manso por el valor de un libramiento de igual cantidad dado en marzo de 1742 a favor de Juan García Romero, vecino de Cádiz. Santiago de Chile, 6 de mayo de 1743.

30 ATHA, F. Samaniego, Caja 39, N. 01. Traslados hechos por Santiago de Santibañez, escribano público de la ciudad de Santiago, a pedimento de D. Diego de Hesles Campero, secretario del Excmo. Sr. D. Joséph Manso. Santiago de Chile, 14 de noviembre de 1744.

31 Diego Barros Arana, Historia General de Chile, t. VI, p. IV, caps. VII y VIII, Santiago, 1866. Dato tomado de Moreno Cebrián: Relación y documentos de gobierno del virrey del Perú, pág. 19. Tal vez la documentación de dichas residencias arroje alguna luz sobre el asunto. Se encuentra en AGI, Escribanía, 942 A, 942B, 942C. Residencias de Gabriel Cano de Aponte y Manuel de Salamanca, gobernadores, capitanes generales y presidentes de la Audiencia de Chile, por José Manso, su sucesor. 1736-1750. 
“Amigo de mi alma: cada día estoy más contento de haber propuesto al Rey fuese vuesa merced Virrey del Perú y S. M. persuadido está a que ha sido muy acertada la elección (...) obre vuesa merced como le dicten su honor y su conciencia, pues aquí se le sostendrá, y represente lo que por sí no puede hacer para que se le envíen las órdenes necesarias". 32

Durante los dieciséis largos años que gobernó el virreinato, Superunda se rodeó de criados, amigos y parientes que le ayudaron a llevar a cabo sus objetivos, tanto en la esfera pública como en la privada, que es el objeto de análisis de este trabajo. No obstante, la delimitación de ambas esferas no es nítida y con frecuencia personas del entorno privado daban "el salto" a la esfera pública, mediante provisiones de oficios hechas por el virrey.

Desde Santiago de Chile le acompañó Diego de Hesles Campero, natural de Abionzo, en el valle de Carriedo - hoy de Villacarriedo—- en las montañas de Burgos. Era aquel fiel criado que con 30 años se embarcó en El Conquistador para viajar con él a Chile. ${ }^{33}$ Allí ejerció como su secretario personal y, una vez en el Perú, como secretario de cámara, uno de los oficios de mayor confianza de la casa virreinal. ${ }^{34}$ En carta "al jefe" de 1746, Manso expresaba el alto aprecio que sentía por esta persona que "llena toda mi confianza con particular amor" e informaba al marqués que le había nombrado brigadier como premio a su lealtad. Por todo ello aprovechaba también para recomendarle a Ensenada para "mayores empleos". ${ }^{35}$

El mayordomo mayor de la casa del virrey en Lima fue Juan Bautista de Casabona, peninsular, nacido en Zaragoza. Debió viajar muy joven a América puesto que al comienzo del gobierno peruano de Superunda tenía

32 AGI, Lima, 642. Carta del marqués de la Ensenada a José Manso de Velasco. San Lorenzo de El Escorial, 30 de noviembre de 1745. Dentro de una carpeta en cuartilla donde está rotulado "A Manso-Particular del jefe".

33 AGI, Contratación 5.483, N. 2, R. 2, f. 11-15v. "Expediente de información y licencia de pasajero a Indias de José Manso, Presidente de la Real Audiencia de Santiago de Chile”. Cádiz, 29 de diciembre de 1736. Por la urgencia del embarque no se pudieron pedir a su tierra natal las pruebas de "naturaleza y libertad". La Casa de la Contratación accedió a considerar válida la información presentada entonces por Ignacio Gallardo, representante de José Manso en Cádiz, basada en las declaraciones de tres testigos. El primero de ellos, Francisco Colarte, paisano de Hesles y residente en Cádiz, era la única persona que afirmaba conocerle desde hacía tiempo a Diego de Hesles y haberle tratado con familiaridad. Aportó de hecho datos exactos sobre su lugar de nacimiento y nombre de sus padres. Los otros dos testigos confirmaban sus noticias pero reconocían conocerle sólo desde hacía diez días.

34 ATHA, F. Samaniego, Caja 39, N. 40. Decreto de Superunda con nombramiento a Francisco Renjifo de alférez de la guardia del Virrey. Lima, 1 de enero de 1760. Aparece Hesles como secretario del virrey.

35 AGI, Lima, 642. Carta de José Antonio Manso de Velasco al marqués de la Ensenada. Lima, 12 de agosto de 1746. 
tan sólo 19 años. Sin embargo, su destacado puesto entre los criados del virrey, le llevó pronto a ser una persona muy conocida en la ciudad, a través de la cual se hacían casi todas las compras y encargos del palacio virreinal. En 1757, Manso recompensó sus servicios nombrándole corregidor y justicia mayor de la provincia de Guamalíes. Casabona hizo testamento en Lima antes de partir a su nuevo destino. Por él sabemos que era soltero y mantenía estrechos vínculos con su ciudad natal. Era, por ejemplo, un gran devoto de la Virgen del Pilar, ${ }^{36}$ como lo demuestra el hecho de que remitiera a Cádiz 2.600 pesos fuertes (52.000 reales de vellón) como limosna para la "fábrica y ornato de su sagrada capilla". También era muy favorable a la Compañía de Jesús de Zaragoza, de cuyo colegio debió ser alumno. ${ }^{37}$ Su cercanía al virrey queda igualmente patente en este documento al nombrarle albacea de todos sus bienes; en caso de que no pudiera hacerse cargo, por sus ocupaciones, transmitía esta obligación a Martín Sáenz de Tejada — que como se verá era la mano derecha del virrey-. El tercer albacea era el entonces conde de San Isidro, Martín de Santiago, uno de los aristócratas más destacados de la sociedad limeña.

Después de ocupar durante un tiempo el corregimiento de Guamalíes, Casabona regresó a la ciudad de los Reyes donde siguió ejerciendo el cargo de mayordomo mayor y contando con la confianza de Manso de Velasco. De hecho, salió del Perú casi un año después que él, con el fin de zanjar sus asuntos económicos en el virreinato. Acertó al elegir la ruta del Cabo de Hornos, con lo que esquivó el ataque inglés a La Habana de 1763, que retuvo a Manso en dicha plaza y fue el comienzo de su triste final. Fue precisamente Casabona, "su más rendido fiel criado" — como él mismo se definía-, quien se hizo cargo del traslado a España del archivo personal del virrey. ${ }^{38}$ Se estableció en Cádiz, donde durante unos años continuó atendiendo los asuntos del conde. Tiempo después regresó al Perú y volvió a

36 ATHA, F. Samaniego, Caja 39, N. 14. Carta de a Juan Bautista de Casabona a D. Juan Agustín de Uztáriz. Lima, 14 de enero de 1754.

37 Archivo General de la Nación de Lima (en adelante AGN), Protocolos Notariales, leg. 1008. E: Juan Bautista Tenorio Palacios. Testamento del general D. Juan Bautista Casabona. Los Reyes, 8 de marzo de 1758. Destinaba 12.000 pesos para que se fundara en Zaragoza una casa de ejercicios de San Ignacio de Loyola, a cargo de los jesuitas y otros 4.000 pesos para invertir en "fincas seguras" cuyos réditos mantuvieran una obra de beneficencia de la que se debía encargar el rector del Colegio de la Compañía de Zaragoza.

38 ATHA, F. Samaniego, Caja 39, N. 23. Carta de Juan Bautista de Casabona al conde de Superunda, Cádiz, 4 de agosto de 1762. Un ejemplo de ello es el expediente que se encuentra en el Archivo Histórico Nacional de Madrid (en adelante AHN), Consejos 20.206. Juan Bautista Casabona contra la quiebra de Olave y Compañía. Cádiz, 1758-1769. 
establecerse en la ciudad de Los Reyes, lo cual confirma sus buenos contactos dentro de la sociedad limeña. ${ }^{39}$

Tal vez el hombre más cercano a Superunda fue Martín Sáenz de Tejada, riojano, nacido en Viguera, localidad de la comarca de Cameros, lindante con Torrecilla. La primera referencia que tenemos de él procede de una carta dirigida al virrey del Perú por el Duque de Sotomayor, Félix Fernando de Masones y Lima, noble de origen italiano, a quien Fernando VI había nombrado, el 27 de julio 1746, embajador en Portugal. A los pocos meses de incorporarse a este puesto, Sotomayor escribe esta carta en la que, además de comunicar a Manso su nombramiento, le recomienda a Martín Sáenz de Tejada, secretario de su antecesor que, casualmente, se embarcaba para el Perú:

"Sujeto de tan apreciables prendas y circunstancias que me han inclinado a interponerme con v.e. a fin de que se sirva atenderle con el favor que v.e. hallase proporcionado a sus méritos y especial habilidad". ${ }^{40}$

El tono de la carta denota un estrecho trato entre el duque y Manso de Velasco, de quien se despide "con el más fervoroso afecto". Es factible que el embajador pensara que su amigo, que ahora ocupaba un puesto tan importante, recibiría cordialmente a un paisano tan próximo, que reunía además tantas cualidades. Sin embargo, lo más probable es que Superunda conociera ya a este miembro de la familia Sáenz de Tejada, una de las más destacadas del Camero riojano. ${ }^{41}$

Sea como fuere, el caso es que desde ese mismo año Martín se encuentra ya en Lima, encargándose de gestiones del virrey y actuando

39 AHN, Órdenes Militares, Caballeros de Santiago, Expediente $n^{\circ}$ 5.292. Expediente para la concesión del hábito a Juan Francisco Micheo y Uztáriz. Tanto la edad de Casabona como la confirmación de su regreso a Lima son datos extraídos de este expediente en el que figura como uno de los testigos interrogados.

40 ATHA, F. Samaniego, Caja 39, N. 16. Carta del Duque de Sotomayor a [José] Antonio Manso de Velasco. Lisboa, 2 de diciembre de 1746. Sotomayor permaneció en Portugal hasta 1752, año en que pasó a ocupar la embajada de París. De regresó a Madrid, recibió el hábito de caballero de Santiago en 1754. Fue promovido a presidente del Consejo de Órdenes en 1765. Ozanam, Didier: Les Diplomates espagnols du XVIIIe siècle: introduction et répertoire biographique, 1700-1808, Casa de Velázquez, Maison des Pays Ibériques, Madrid, Bordeaux, 1998, pág. 346. Véase también, Ozanam, Didier: Un español en la corte de Luis XV: cartas confidenciales del embajador Jaime Masones de Lima, 1752-1754, Publicaciones de la Universidad de Alicante, San Vicente del Raspeig (Alicante), 2001.

41 El origen de la familia se remonta al siglo XV y al solar de Valdeosera, un señorío ubicado en pleno corazón de la Sierra de Cameros, cuya primera confirmación real dio Enrique IV en 1460. El solar tenía 368 ha. y rendía 1.575 reales anuales Ibañez Rodríguez, et al.: Los señoríos en La Rioja en el siglo XVIII, págs. 90 y 96. 
como su mayordono y secretario personal. Fue además nombrado por Superunda capitán de artillería de Lima. Todo parece indicar que el virrey le encomendó la gestión de los asuntos relacionados con su familia, a la que Martín además conocía perfectamente. Así se desprende, por ejemplo, de una carta de 1758 en la que se dirige a Félix Manso de Velasco, sobrino del virrey, tratándole de "paisano, dueño y señor" y trata un tema tan cercano como el impacto que en Superunda había tenido la noticia del fallecimiento de su hermano Diego, padre de Félix, a pesar de su quebrada salud: "no obstante haber salido del continuo padecer en que le tenían sus accidentes". En esa misma misiva Martín le pide a Félix que averigüe un asunto relacionado con un paisano establecido en el virreinato. ${ }^{42}$ Familia y paisanaje son dos fuertes elementos que conectan a este criado con el virrey.

Al igual que Casabona, Sáenz de Tejada dejó el Perú al finalizar el gobierno de Superunda. Sin embargo, mientras otras personas parecen alejarse del entorno de Manso de Velasco en los últimos y difíciles años de su vida, Martín le acompañó hasta su muerte en 1766; ${ }^{43}$ incluso, más de diez años después, continuará haciéndose cargo de algunos de sus asuntos. En 1767 Carlos III le concedió el hábito de alguna de las órdenes militares y eligió la de Santiago. Esta merced confirmaba su origen noble, y cómo no olvidarlo, el respaldo del duque de Sotomayor, su anterior señor, presidente entonces del Consejo de Órdenes. ${ }^{44}$

Estrechamente ligado a Sáenz de Tejada está Juan de Albarellos y Soto, también natural de Viguera, probablemente criado del anterior. Formó parte de la casa del conde de Superunda en Lima hasta que en 1752, cuando se establece en el Perú la oficina del estanco de tabaco, el virrey le nombró oficial mayor y secretario de esta entidad, con 1.200 pesos anuales de sueldo. ${ }^{45}$ Cuando en 1760, antes de salir del virreinato, Manso deje

42 ATHA, F. Samaniego, Caja 39, N. 21. Carta de Martín Sáenz de Tejada a Félix José Manso de Velasco, Lima, 6 de abril de 1758. Por ejemplo, en esta carta pide a Felix —a instancias de uno de los interesados - que averigüe en qué estado se hallaba el mayorazgo fundado por D. Pedro Ambrosio Bilbao la Vieja, "nuestro paisano", que había fallecido recientemente en la ciudad de La Paz.

43 ATHA, F. Samaniego, Caja 40, N. 29. "Encargo privado que yo el conde de Superunda hago a D. Martín Sáenz de Tejada y D. Juan de Albarelos sobre el destino y aplicación que por mi fallecimiento deverán dar a los cortos vienes y alajas de mi actual servicio que aquí se expresarán en la forma siguiente", Priego de Córdoba, 16 de enero de 1766.

44 AHN, Órdenes Militares, Caballeros de Santiago, Expedientillo no 7.985. Por el expediente que se conserva, bastante reducido, sabemos que la concesión del hábito está fechada en San Idelfonso, a 1 de septiembre de 1767. Se dice que es natural de Torrecilla de los Cameros e hijo de Manuel Sáenz de Tejada y Josepha García Morales, oriundos de la misma villa. Sin embargo, en la documentación del virrey figura siempre como natural de Viguera. Tal vez en ese momento este último municipio dependiera de Torrecilla. 
hecho codicilo, que completara su testamento de 1752, le nombrará albacea detrás de Martín Sáenz de Tejada. ${ }^{46}$ Desde entonces, en los documentos personales del ex-virrey el nombre de Albarellos seguirá siempre al de Sáenz de Tejada. Ambos se trasladaron a vivir a Logroño tras el fallecimiento de Superunda ${ }^{47}$ quien en agradecimiento a sus servicios les dejó "de los cortos vienes y alajas" que le quedaban, a Martín Sáenz de Tejada, su cama con dosel de colgaduría de seda de china "que actualmente tengo en uso" - un regalo que, de nuevo, denota la cercanía entre criado y señor-; a Albarellos una caja de oro labrada para tabaco, muestra de una menor amistad. ${ }^{48}$

Como se verá más adelante, algunos de estos criados de Superunda se encargarán de actuar como agentes del virrey para operaciones de tipo mercantil. Sin embargo, Manso de Velasco siempre tuvo especial contacto con algunos comerciantes que, en gran medida, también encubrieron sus negocios. No son por tanto, en principio, personas del entorno del virrey, de su familia o casa, pero sí hombres a los que se confían negocios fraudulentos.

\section{Agentes comerciales en Lima y Cádiz}

El tráfico con el virreinato peruano experimentó durante la primera mitad del siglo XVIII una importante transformación desde las concesiones hechas al comercio francés durante la Guerra de Sucesión, que luego fueron muy difíciles de erradicar, hasta la implantación del sistema de registros como consecuencia de la destrucción de Portobelo en 1739, al inicio de la llamada Guerra de la Oreja, que supuso en la práctica la sustitución definitiva de los Galeones - que se habían intentado relanzar con el Proyecto de 1720 - por los navíos que viajaban "sueltos" a Cádiz, siguiendo preferentemente la ruta del Cabo de Hornos. Según señala con acierto Carmen Parrón, el cambio fue tan drástico que lo único que realmente se

45 Moreno Cebrián: Relación y documentos de gobierno del virrey del Perú, pág. 364.

46 AGN, Protocolos Notariales, leg. 598. E: Francisco Luque. Copia en ATHA, F. Samaniego, Caja 40, N. 07. Codicilo de José Antonio Manso de Velasco, conde de Superunda. Los Reyes, 29 de abril de 1760. En cambio no aparece Albarellos como albacea en el testamento, sí Sáenz de Tejada. ATHA, F. Samaniego, Caja 40, N. 04. Testamento José Antonio Manso de Velasco, virrey del Perú. Los Reyes, 24 de febrero de 1752.

47 ATHA, F. Samaniego, Caja 39, N. 04. Escritura de cesión de 160.000 reales a Josefa Samaniego por parte de Martín Sáenz de Tejada y Juan de Albarellos, cumpliendo la voluntad del conde de Superunda. Logroño, 19 de noviembre de 1777.

48 ATHA, F. Samaniego, Caja 40, N. 29. "Encargo privado que yo, el conde de Superunda, hago a D. Martín Sáenz de Tejada y D. Juan de Albarelos...”, Priego de Córdoba, 16 de enero de 1766. 
mantuvo, con respecto al monopolio anterior, fue el sistema de puerto único. Como la nueva vía ofrecía inmejorables perspectivas para artículos como la cascarilla y el cacao de Guayaquil y el cobre chileno, desde 1750 este comercio experimentó un considerable auge. La consecuencia fue inmediata: durante las tres décadas siguientes, aproximadamente hasta 1770, se establecieron en Lima un gran número de españoles como representantes de casas gaditanas. Pronto los intereses de los comerciantes limeños toparon con los del "comercio de Cádiz" en Lima. Sin embargo, ambas partes acabaron optando por sumar fuerzas, conscientes de que esa era la única manera de mantener un comercio tan lucrativo. ${ }^{49}$ En ese contexto tiene lugar el gobierno de José Antonio Manso de Velasco en el Perú. ${ }^{50}$

Entre los comerciantes con los que tuvo Superunda relaciones de negocios destaca, en primer lugar, la figura de Martín de Celayeta Basagoitia y Aldecoa. Los primeros envíos de Manso de Velasco a España se van a hacer siempre a través de este vizcaíno, nacido en 1681 en Amorebieta - perteneciente entonces a la diócesis de Calahorra- Parece que Celayeta se estableció en Lima antes del auge anteriormente mencionado y llegó a ser un comerciante conocido, con tienda propia y un caudal considerable. ${ }^{51}$ En 1736 fue nombrado caballero de la orden de Santiago. En ese momento aparece ya en la documentación como residente en Lima. Sin embargo, ninguno de los seis testigos procedentes del virreinato que, de paso por Madrid, fueron interrogados acerca de las actividades del pretendiente en la capital virreinal reconocen que se dedicara al comercio, como es lógico. Todos ellos en cambio coincidían en señalar que tenía 55 años y era capitán de milicias de la ciudad de Lima, donde vivía "con lustre" y era conocido como "buen cristiano". ${ }^{52}$ No es de extrañar que entre estos seis testigos aparezcan dos nombres muy vinculados

49 El tema ha sido brillantemente trabajado para este momento por Parrón Salas, Carmen: "Perú y la transición del comercio político al comercio libre", Anuario de Estudios Americanos, 54, Sevilla, 1997, págs. 456-457 y 460-461.

50 Sobre Superunda y el Consulado de Lima véase: Moreno Cebrián: Relación y documentos de gobierno del virrey del Perú, págs. 112-113.

51 Turiso Sebastián, Jesús: Comerciantes españoles en la Lima borbónica: anatomía de una elite de poder (1701-1761), Universidad de Valladolid, Secretariado de Publicaciones e Intercambio Editorial, Valladolid, 2002, pág. 300.

52 AHN, Órdenes Militares, Caballeros de Santiago (1737), Expediente n ${ }^{\circ} 1.854,652$ fs. Por el expediente constaba también que era hijo de Juan de Celayeta de Basagoitia, regidor, síndico de Amorebieta, y María de Aldecoa, naturales ambos de Amorebieta. Para valorar la importancia social de los militares véase Gálvez, José Francisco: "Burócratas y militares en el siglo XVIII", Scarlett O’Phelan Godoy (comp.): El Perú en el siglo XVIII. La Era Borbónica, Pontificia Universidad Católica del Perú, Instituto Riva Agüero, Lima, 1999, págs. 243-262. 
con el comercio de Lima, los de Diego de Orbea ${ }^{53}$ y Juan José de Molleda y Clerque. ${ }^{54}$ Apenas disponemos de algún dato biográfico más de Martín de Celayeta, extraído de su testamento. Por él consta que nunca se casó ni tuvo descendencia. Llevó una activa vida religiosa como mayordomo de la famosa cofradía Nuestra Señora de Aránzazu en Lima. ${ }^{55}$ A su muerte legó considerables sumas de dinero a instituciones religiosas y benéficas de la ciudad..$^{56}$

El comerciante gaditano a quien José Manso de Velasco va a remitir sus partidas será Juan Agustín de Uztáriz, miembro destacado de la poderosa saga de comerciantes navarros que se establecieron en Cádiz en la década de los treinta del siglo XVIII. ${ }^{57}$ Según ha demostrado recientemente Victoria Martínez del Cerro, los Uztáriz más conocidos pertenecen a dos generaciones de una misma familia. ${ }^{58}$ Todos ellos descienden de Miguel de Uztáriz y María Vértiz, que tuvieron cuatro hijos: Pedro, Carlos, José y Juan Bautista Uztáriz Bertiz. Los tres primeros hermanos aparecen matriculados en el Consulado de Cádiz en 1730, constituyendo la primera generación que se traslada a esta ciudad..$^{59}$ Juan Bautista, en cambio, permaneció en Navarra y

53 Otro conocido comerciante vasco, natural de Eibar (Guipúzcoa), establecido en la ciudad de Los Reyes. Desde 1715 disfrutaba de un cargo oficial en el corregimiento de Chachapoyas que compró por 2.000 pesos. Su hijo Diego pagó en $1749,41.400$ pesos por una plaza supernumeraria de la sala del crimen de la Audiencia de Lima, éste Diego de Orbea llegaría a ser caballero de la orden de Santiago en 1762. Turiso Sebastián: Comerciantes españoles en la Lima borbónica, pág. 321. Véase también Moreno Cebrián: Relación y documentos de gobierno del virrey del Perú, pág. 457.

54 Compró el corregimiento del Cuzco en 1748; era, a su vez, hijo de otro destacado comerciante español establecido en Lima, Juan de Molleda Rubín de Celis. Luego fue corregidor de Lima. Véanse Turiso Sebastián: Comerciantes españoles en la Lima borbónica, pág. 317 y Lohmann Villena, Guillermo: Los americanos en las órdenes nobiliarias, Consejo Superior de Investigaciones Científicas, Madrid, 1993, pág. 32.

Los otros testigos americanos eran o habían sido residentes en Lima: Andrés de Uribe y Vergara —abogado de los reales consejos_- Antonio Jacinto Arias Pérez — caballero de Santiago, véase Lohmann Villena: Los americanos en las órdenes nobiliarias, págs. 31-32- y Diego Arandia. Tan sólo uno de ellos, Ignacio de la Escalera, residía en Quito. En Amorebieta fueron interrogados después 28 testigos de la localidad.

$55 \mathrm{La}$ importancia social de esta cofradía ha sido estudiada por Luque Alcaide, Elisa: "Coyuntura social y cofradía. Cofradías de Aránzazu de Lima y México", Pilar Martínez López-Cano, Gisela von Wobeser, Juan Guillermo Muñoz (coords.): Cofradías, capellanías y obras pías, Universidad Nacional Autónoma de México, Instituto de Investigaciones Históricas, México, 1998, págs. 91-108.

56 Turiso Sebastián: Comerciantes españoles en la Lima borbónica, págs. 205-206.

57 Ruiz Rivera: El Consulado de Cádiz, pág. 126.

58 Martínez del Cerro, Victoria: Una comunidad de comerciantes: navarros y vascos en Cádiz (segunda mitad del siglo XVIII), Tesis doctoral inédita, Departamento de Historia, Universidad de Navarra, 2003. En concreto la información que se utiliza procede del capítulo VII: Los Uztáriz. una dinastía de hombres de negocios. Agradezco a la autora de este trabajo las facilidades dadas para consultarlo antes de su publicación. 
se casó con María Francisca de Gaztelu ${ }^{60}$ lo cual permitió a los Uztáriz entroncar con los propietarios de la casa-palacio de Reparacea. ${ }^{61}$ Tres hijos de Juan Bautista ${ }^{62}$ se fueron trasladando a Cádiz, amparados por el negocio comenzado por sus tíos. Esta segunda generación aparece matriculada en distintas fechas en el Consulado: Juan Bautista y Juan Felipe en 1755, posteriormente Juan Francisco (1760) y más tarde José Joaquín (1763). ${ }^{63}$

Los que llegaron a Cádiz en la segunda mitad del siglo van a comenzar a trabajar con su primo Juan Agustín, ${ }^{64}$ quien ya figura matriculado en el Consulado desde 1739. De mayor edad y experiencia en la ciudad y su comercio, Juan Agustín fue el primero de los primos en establecer negocios comerciales. En 1750 desempeñaba el importante cargo de apoderado en Cádiz de los Cinco Gremios Mayores de Madrid para todo lo referente al comercio indiano. Con el apoyo de esta institución logró crear en 1752 su compañía propia, Uztáriz y Compañía, con un capital de 15 millones de reales de vellón (de los que 2/3 partes fueron aportados por los Cinco Gremios y el resto por Uztáriz) y una duración prevista de seis años. Sus primos se fueron involucrando en estos negocios progresivamente. ${ }^{65} \mathrm{Se}$ calcula que mantuvo un volumen comercial de 6.000 pesos anuales (90.352 reales de vellón) entre 1753 y 1762. Cumplido el plazo, en 1759 la Compañía quedó disuelta ${ }^{66}$ pero los primos Uztáriz articularon alianzas a través de nuevas compañías para seguir compitiendo en el comercio con América. ${ }^{67}$

59 Naturales de Narbarte y Oyeregui respectivamente; dos pequeñas localidades, colindantes, del valle de Bertizarana en el noroeste de Navarra.

60 Hija de Pascual Gaztelu, de Narvarte y Graciana Albiera, de Legasa. Este último municipio se encuentra en el mismo valle.

61 La denominación de palacio se utiliza en la zona para referirse a las casas solariegas de las familias nobles. El palacio de Reparacea existe en la actualidad. Se refirió ya a él Caro Baroja, Julio: La hora navarra del XVIII: personas, familias, negocios e ideas, Institución Príncipe de Viana, Pamplona, 1985, pág. 315.

62 Tuvo cinco hijos varones: Juan Bautista, Juan Felipe, Juan Miguel el "mayor", Juan Francisco, José Joaquín y Juan Miguel "el menor".

63 Ruiz Rivera: El Consulado de Cádiz, pág. 210.

64 Hijo de José Uztáriz Bértiz, perteneciente a la primera generación, y Joaquina Micheo. Se trasladó a Cádiz con sus padres siendo todavía muy joven.

65 Martínez del Cerro: Una comunidad de comerciantes: navarros y vascos en Cádiz, cap. VII.

66 Bustos Rodríguez, Manuel: Los comerciantes de la carrera de Indias en el Cádiz del siglo XVIII (1713-1775), Servicio de Publicaciones de la Universidad de Cádiz, Cádiz, 1995 pág. 241.

67 En 1762 la firma se convirtió en administradora y productora de bienes industriales al adquirir por contrato las Reales Fábricas de Talavera de la Reina de Toledo. Ruiz Rivera, Julián B.: "La Compañía de los Uztáriz, las reales fabricas de Talavera y el comercio con Indias", Anuario de Estudios Americanos, 36, Sevilla, 1979, pág. 220. Véanse de este mismo autor "La casa de Uztáriz, San Ginés 
Dos fueron los miembros de esta segunda tanda que alcanzaron una mayor distinción social, apoyada en sus negocios y potenciada por sus enlaces matrimoniales. El primero es, lógicamente, Juan Agustín Uztáriz Micheo, el socio gaditano de Superunda, quien el mismo año que Manso llegaba al Perú —en 1745- contraía matrimonio en Cádiz con María Arroyave, hija de otro destacado hombre de negocios gaditano, Miguel de Arroyave, y hermana del conde de Mirasol. ${ }^{68}$ En 1763 recibió el título nobiliario de marqués de Echandia. ${ }^{69} \mathrm{El}$ otro fue Juan Bautista Uztáriz Gaztelu, que se casó en 1758 con María Pascuala Aristegui, hija del guipuzcoano Lorenzo de Aristegui, un comerciante asentado en Cádiz desde $1737 .{ }^{70}$ En 1763 fue nombrado conde de Reparaz — por la casa de Reparacea—. Como no tuvo hijos, el conde dedicó gran parte de su fortuna a la construcción de la llamada "Santa Cueva", de la que se hablará más adelante, y mandó hacer en la iglesia del Rosario un altar con ricos mármoles, dedicado al patrón de Navarra, San Francisco Javier. ${ }^{71}$

Sin embargo, para el tema que nos ocupa existe otro miembro del clan Uztáriz que tuvo también relevante protagonismo en los negocios del conde de Superunda. Se trata de Juan Francisco de Micheo Uztáriz, nacido en Gaztelu en 1712, hijo de Fernando de Micheo y María Cathalina de Uztáriz Bértiz - hermana de los que conformaron la primera generación de Uztáriz gaditanos- Juan Francisco era por lo tanto primo carnal de todos los Uztáriz de la segunda generación. ${ }^{72}$ En 1743 se matriculó en el Consulado y ese mismo año fue a Buenos Aires para hacerse cargo de diversas mercancías, enviado por Juan Agustín; ${ }^{73}$ en 1749, pasó a Nueva España avalado por Juan Bautista, con mercaderías "propias y de otros interesados". ${ }^{74}$

y Compañía” en La burguesía mercantil gaditana (1650-1868). Ponencias presentadas en el XXXI Congreso Luso-Español para el Progreso de las Ciencias, celebrado en Cádiz, Instituto de Estudios Gaditanos, Cádiz, 1976, págs. 183-197 y "Rasgos de modernidad en la estrategia comercial de los Uztáriz, 1766-1773”, Temas americanistas, 3, Sevilla, 1983, págs, 12-17.

68 Aparece matriculado en el Consulado en 1730. Ruiz Rivera: El Consulado de Cádiz, pág. 114.

69 Su mujer murió en 1759 después de nacer Miguel José. El título de Echandia procedía del barrio del mismo nombre, en Narbarte, donde se situaba la casa de esta rama de la familia.

70 Ruiz Rivera: El Consulado de Cádiz, pág. 114.

71 Garmendia Arruebarrena, Jose: Vascos en Cádiz: (siglos XVII-XVIII), Sociedad Guipuzcoana de Ediciones y Publicaciones, San Sebastián, 1986.

72 AHN, Órdenes Militares, Caballeros de Santiago, Expediente n ${ }^{\circ}$ 5.292. Expediente de ingreso en la orden de Santiago de Juan Francisco Micheo y Uztáriz. Madrid, 28 de marzo de 1767.

73 AGI, Contratación, 5486, N. 2, R. 40. Expediente de información y licencia de pasajero a Indias de Juan Francisco Micheo y Uztáriz, con su criado Lorenzo Ruiz Tagle, natural de Torre la Vega a Buenos Aires. Cádiz, 30 de agosto de 1743.

74 AGI, Contratación, 5.490, N. 2, R. 14. Expediente de información y licencia de pasajero a Indias de Juan Francisco Micheo y Ustáriz, mercader. Cádiz, 23 de mayo de 1749. 
Pero es en 1751 cuando Juan Francisco da definitivamente el salto al Perú con el fin de representar en Lima los intereses comerciales de la familia. El entonces cabeza del clan, Juan Agustín, escribe a Juan Bautista de Casabona, mayordomo de Manso de Velasco, pidiéndole que proteja a su pariente y le recomiende ante el virrey ${ }^{75} \mathrm{Al}$ año siguiente, aprovechando otro embarque, agradece a Casabona la confianza depositada por él y "el amigo Martín de Celayeta" en Juan Francisco y le asegura será deudor de "quantto practicare vmd. en veneficio de dcho. mi primo". ${ }^{76}$

A partir de ese momento Juan Francisco aparece vinculado con los embarques a Cádiz que los agentes del virrey hacen desde Lima ${ }^{77}$ se instala en el virreinato y entra a formar parte del círculo de amistades de Superunda; fue de hecho uno de sus fiadores en el juicio de residencia. ${ }^{78} \mathrm{En}$ 1767, año en que continuaba residiendo en Lima y era capitán de milicias de la ciudad, recibió el hábito de la orden de Santiago. Los catorce testigos vinculados con la familia, que fueron interrogados en diferentes localidades navarras, coincidían en destacar el "lustre" de los Uztáriz y en afirmar que ni el pretendiente ni ningún otro miembro de la saga: "no han sido en tiempo alguno mercaderes ni cambiantes ni han ejercido oficio bil mecánico". El propio Juan Bautista de Casabona que — de paso por la corte - fue interrogado para las pruebas, no dudó en corroborar lo anterior y declarar que había pasado al Perú:

"en solicitud de ciertos Yntereses y Posesiones que le dexaron diversos parientes empleados con el mayor honor en el servicio de S.M., y con el mismo se ha mantenido y mantiene, sin exercer oficio vil o mecánico que le obste a su pretensión, antes bien sabe se halla mui estimado e yntroducido con todos los Sres. Birreyes de aquel Reyno y con las familias de la principal nobleza...". ${ }^{79}$

Juan Francisco se acabó casando en 1787, a la edad de setenta y cinco años, con la criolla limeña Joséfa Jiménez Lobatón, sobrina de Agustín

75 ATHA, F. Samaniego, Caja 39, N. 19. Carta de Juan Agustín de Uztáriz a Juan Bautista de Casabona sobre asuntos de embarques. Cádiz, 4 de noviembre de 1751. AGI, Contratación, 1.744. Registros de ida a puertos del Mar del Sur desde Cádiz. N. 1, Año de 1751: Juan Francisco de Micheo Uztáriz, en el navío Jesús, María y José.

76 ATHA, F. Samaniego, Caja 39, N. 26. Carta de Juan Agustín de Uztáriz a Juan Bautista de Casabona sobre asuntos de embarques. Cádiz, 6 de mayo de 1752.

77 ATHA, F. Samaniego, Caja 39, N. 19. Carta de Juan Agustín de Uztáriz a Juan Bautista de Casabona. Cádiz, 4 de noviembre de 1751.

78 Así consta en: AGI, Lima, 787. Residencia del conde de Superunda, virrey del Perú. Expediente N. 1. Memorial de José Boza y Garcés, apoderado de José Antonio Manso de Velasco.

79 AHN, Órdenes Militares, Caballeros de Santiago, Expediente ${ }^{\circ} 5.292$ Expediente de ingreso en la orden de Santiago de Juan Francisco Micheo y Uztáriz. Madrid, 28 de marzo de 1767. 
de Salazar y Muñatones, primer conde de Monteblanco, que había sido también uno de los fiadores de la residencia de Superunda. En ese momento tenía el nombramiento de coronel del regimiento del Comercio de Lima. Emparentó así con una familia de la "principal nobleza" de la ciudad. Su única hija, Juana de Micheo y Jiménez Lobatón, estuvo a punto de convertirse en la marquesa de San Juan Nepomuceno, pero falleció antes de que tuviese lugar el enlace. ${ }^{80}$

El entramado de contactos del virrey Manso de Velasco con el comercio ultramarino se completa finalmente con la figura de Pedro Sáenz de Santa María, que al igual que los Uztáriz formaba parte de una de las familias con mayor número de personas trasladadas a Cádiz en el XVIII. ${ }^{81}$ Los Sáenz de Santa María eran riojanos, de Sierra de Cameros y en concreto oriundos de la localidad de Viguera. ${ }^{82}$ Pedro Sáenz de Santa María llegó a ser un poderoso comerciante.

Comenzó su carrera en Veracruz donde logró reunir una sólida fortuna que consolidó con el nombramiento de capitán de las milicias y el cargo de alcalde de primer voto en el cabildo de la ciudad. En 1726 se casó en Veracruz con Ignacia Sáenz Rico, natural de Veracruz de padre español y madre criolla. El matrimonio tuvo cuatro hijos y, al poco tiempo, Pedro se quedó viudo (1739). Aún así permaneció en la Nueva España hasta 1751, año en que se estableció en Cádiz. Entró a formar parte del Consulado de esta ciudad en $1754 ;^{83}$ su habilidad para los negocios le permitió reunir pronto una considerable fortuna ${ }^{84}$ que invirtió en bienes inmuebles - tres

80 Se casó en primeras nupcias con José de Rezábal y Ugarte —oidor de Lima y después regente de la Audiencia de Chile-. Juana falleció en 1804, antes de casarse en segundas nupcias con Manuel Antonio de Arredondo y Pelegrín, también regente de la Audiencia de Lima, caballero de la orden de Carlos III y marqués de San Juan de Nepomuceno. Lohmann Villena, Guillermo: Los ministros de la Audiencia de Lima en el reinado de los Borbones (1700-1821). Esquema de un estudio sobre un núcleo dirigente, Escuela de Estudios Hispanomericanos, Sevilla, 1974, pág. 117. Para las estrategias de ascenso social de los comerciantes limeños véase Mazzeo de Vivó, Cristina: "Mecanismos de supervivencia de la élite mercantil limeña a finales del siglo XVIII y principios del XIX”, Christian Büschges y Bernd Schröter (eds.): Beneméritos, aristócratas y empresarios. Identidades y estructuras sociales de las capas altas urbanas en América hispánica, Iberoamericana, Francfort/Main/Madrid, 1999, págs. 67-82.

81 Ruiz Rivera, Julián Bautista y Manuela Cristina García Bernal: Cargadores a Indias, Mapfre, Madrid, 1992, pág. 275. Fueron en total seis los Saénz de Santa María matriculados en el Consulado de Cádiz entre 1744 y 1790: Juan en 1744, Antonio en 1750, Pedro Manuel en 1763, Juan Manuel en 1770, Juan Antonio en 1775 y José en 1790. Bustos Rodríguez: Los comerciantes de la carrera de Indias, pág. 247. Viguera.

82 Hijo de Marcos Sáenz de Santa María y de Ana de Almarza y Tejada, vecinos ambos de

83 Ruiz Rivera: El Consulado de Cádiz, pág. 202.

84 Se encontraba entre los 25 comerciantes españoles que manejaban casi todo el capital. Ibídem pág. 95 y Bustos Rodríguez: Los comerciantes de la carrera de Indias, págs. 238-241. 
casas en Cádiz- y, sobre todo, en tierras, tal vez lo más llamativo, por ser poco frecuente. En 1763 el comerciante riojano compró por 5.000.000 reales de vellón, una dehesa llamada Zacatena en La Mancha (Daimiel), con la que fundó un mayorazgo. Uno de los "aprovechamientos" de la finca eran los pastos, que alimentaban a 10.859 ovejas y carneros ${ }^{85}$ Visto así, la inversión estaba más que justificada porque Pedro Sáenz de Santa María se estaba haciendo terrateniente para completar el negocio de la ganadería lanar trashumante de su región de origen.

Sin embargo, por diversas y complejas circunstancias, el vínculo del mayorazgo se rompió al fallecer Pedro Sáenz de Santa María en 1785 y su hijo Pedro José en 1787. Agotados los posibles herederos, tanto hijos como nietos, sólo quedaba su hijo menor, José Marcos, que era sacerdote. Fue éste quien, contra todo lo previsto, recibió por herencia la mitad del mayorazgo de Zacatena, más otras tierras anexas que había comprado su padre y la casa de la calle del Rosario. Una fortuna que sumaba un total de 3.795.384 reales de vellón. Era un hombre rico, aunque sólo podía disponer de las rentas, que sumaban anualmente 60.000 reales de vellón. Además recibió el título de segundo marqués de Valde-Íñigo por muerte de su sobrino. ${ }^{86}$

Desde 1771, José Marcos se había vinculado con la Congregacion del Retiro Espiritual, cuyo director era - como se vio- el conde de Reparaz. Esta asociación de seglares, vinculada a la parroquia del Rosario, organizaba diversos ejercicios piadosos. Como no tenía un lugar apropiado para sus reuniones, Uztáriz fomentó la construcción de una nueva sede que se llamó la "Santa Cueva". Se ha especulado mucho acerca del mecenazgo de la Santa Cueva, que tradicionalmente se había atribuido a José Marcos Sáenz de Santa María. Sin embargo, las recientes investigaciones de Manuel Ravina Martín demuestran que en un primer momento el proyecto y la financiación de la iglesia fueron obra de Juan Bautista de Uztáriz, quien siempre quiso permanecer en el anonimato. Más tarde, tras la quiebra del conde y la herencia recibida por José Marcos Sáenz de Santa María, fue éste quien se hizo cargo de la obra ${ }^{87} \mathrm{La}$ Santa Cueva es todavía hoy una joya artística del neoclásico andaluz, obra del arquitecto Torcuato

85 Archivo Histórico Provincial de Cadiz (en adelante AHPC), Protocolo Notarial 2.568b fs. 504-539. Testamento de Pedro Sáenz de Santa María. Cádiz, 10 de agosto de 1784.

86 Ravina Martín, Manuel: "Las finanzas del segundo marqués de Valde-Íñigo", La Santa Cueva de Cádiz, Fundación Caja Madrid, Madrid, 2001.

87 Ibídem. 
Benjumeda. En su interior hay cuadros de Goya y de José Camarón y esculturas de Juan Galdulfo y Manuel González "el granadino". Para ella compuso música Franz Joséph Haydn. Fue decorada con lámparas de araña de la Real Fábrica de la Granja y en la fachada de la capilla se colocó un cuadro de la Virgen del Refugio pintado por Franz Javier Riedmayer. ${ }^{88}$

Este mecenazgo enlaza a los Úztáriz con otro hombre clave de Superunda, Pedro Sáenz de Santa María. Pero no es éste el único vínculo que relaciona al comerciante riojano con la familia de comerciantes navarros. Uno de los hijos de Pedro Sáenz de Santa María, ${ }^{89}$ Ignacio José, se casó en 1751 con Ana Joaquina de Arizcun, hija del segundo marqués de Iturbieta, un navarro de origen baztanés bien situado en la corte. ${ }^{90}$ Así, Pedro Sáenz de Santa María no sólo emparentó con la nobleza navarra de Madrid sino que tuvo que compartir con el marqués el cuidado de su nieto, Manuel Joaquín Sáenz de Santa María Arizcun, que se quedó huérfano a los dos años. Esto le exigió continuos desplazamientos a la corte. ${ }^{91}$ Por otro lado su hijo Pedro José se instaló igualmente en Madrid; ${ }^{92}$ fue caballero de la orden de Santiago y trabajó como "mayordomo de semana" en el Palacio Real; en la práctica vivió a expensas de su rico padre que le encargó de administrar sus fincas. Además nos consta que Pedro Sáenz de Santa María tenía relación de negocios con Juan Miguel Uztáriz Gaztelu, agente de sus hermanos y primo en Madrid, a quien en 1762, otorgó, junto con otras dos personas, un poder especial para que gestionara la compra de la dehesa Zacatena. ${ }^{93}$

88 Torralba Soriano, Francisco: Francisco de Goya en la Santa Cueva, Cádiz, Zaragoza, Banco Zaragozano, 1983; Alonso de la Sierra Fernández, Lorenzo: "El retablo gaditano del neoclasicismo", Imafronte. Revista de Historia del Arte, 3-5, Murcia, 1987-1989, págs. 447-467.

89 AHPC, Protocolo Notarial 2.568b fs. 504-539. Testamento de Pedro Sáenz de Santa María. Cádiz, 10 de agosto de 1784. Pedro Sáenz de Santa María tuvo cuatro hijos, nacidos en Veracruz: Francisca Javiera (1728-1766), Ignacio José, Pedro José (1736) y José Marcos (1738). La mayor se casó con Francisco Gil López, comerciante de Veracruz, y tuvo con él ocho hijos. Ignacio José y Pedro José se instalaron y casaron en Madrid. José Marcos se hizo sacerdote y vivió siempre con su padre.

90 El primer marqués de Iturbieta, título concedido en 1741, fue Miguel de Arizcun que murió sin descendencia y pasó el título y el mayorazgo fundado por él a su hermano Francisco, segundo marqués, que se casó con María Joséfa de Irigoyen. Caro Baroja: La hora navarra del XVIII, págs. 266-284.

91 AHPC, Protocolo Notarial 2.568b fs. 504-539. Testamento de Pedro Sáenz de Santa María. Cádiz, 10 de agosto de 1784. En 1775 se casó con Joséfa de Muro y Salazar, con la que tuvo tres hijas. Sin embargo, Manuel Joaquín murió el 21 de enero 1780 en Madrid, con tal sólo 25 años y poco después fallecieron también sus hijas.

92 AHPC, Protocolo Notarial 2.568b fs. 504-539. Testamento de Pedro Sáenz de Santa María. Cádiz, 10 de agosto de 1784. Se casó en 1770 con María Moreno Daoiz, pero no tuvieron descendencia. 93 AHPC, Protocolo Notarial 895. 1762. Poder especial otorgado por Pedro Sáenz de Santa María. Cádiz, 1762. 
El papel de Pedro fue precisamente el de hacer de enlace entre la firma Uztáriz y los Manso de Velasco. En cierto modo, Pedro continuaba en Cádiz el papel de contacto con la familia que, desde Lima, llevaba a cabo Martín Sáenz de Tejada. No olvidemos que ambos procedían de la misma localidad riojana, Viguera, y conocían por lo tanto a la familia del virrey, residente en Torrecilla. La desahogada situación económica de Pedro en Cádiz y su vinculación con La Rioja le hacían especialmente idóneo para su función; además, era también una persona con muchas relaciones en Madrid y, por lo tanto, podía ser también el contacto con la corte, es decir, con su también paisano, el marqués de la Ensenada. De hecho, la vinculación de Pedro, más que con Manso de Velasco, fue con Martín Sáenz de Tejada.

Una prueba de todo lo que se acaba de decir es la carta que Sáenz de Tejada remite a Sáenz de Santa María desde Lima en abril de 1758 en la que le comunicaba que "deseoso el conde de Superunda mi amo de manifestar en alguna parte lo agradecido que está a v.m. por la generosidad con que ha caminado en los suplementos que hizo en los asuntos que le interesan a S.Ex.", le había ordenado hacerle algún regalo; con ese motivo le remitía un cajón arpillado, rotulado a su nombre, que contenía una imagen de Nuestra Señora de Copacabana con su caja de plata y algunas otras piezas de plata y oro, "como muestra de la gratitud del virrey" ${ }^{94}$ Seis meses después, el interesado agradece el generoso gesto del virrey que "es mucho más de lo que mi deseo pudiera esperar". Además el cajón debía contener una sorpresa para el intermediario gaditano, algo que tampoco se registra a la salida del Callao: unos pequeños retratos, "las caras" de Manso de Velasco y Martín Sáenz de Tejada que había enviado al Puerto de Santa María "para que las viese aquel Señor". Sáenz de Santa María se está refiriendo, claro está, al marqués de la Ensenada, que vivió entre 1757 y 1760 en esta localidad, durante su primer destierro de la corte. Ensenada le explicó que ya había recibido el retrato del virrey y ambos se quedaron luego hablando "despacio". ${ }^{95}$ Probablemente ya se conocían, según se apuntará más adelante.

94 ATHA, F. Samaniego, Caja 39, N. 09. Carta de Martín Sáenz de Tejada a Pedro Sáenz de Santa María. Lima, 6 de abril de 1758; Conocimiento de embarque hecho por Antonio de Larrea, vecino de Cádiz, maestre del San Bruno. Lima, 30 de marzo de 1758. El contenido del cajón arpillado era: un taller de plata sobredorada con distintas piezas y un remate en forma de azucena de plata blanca (42 marcos y 4 onzas de peso), una tabla de tinteros de plata con varias piezas (25 marcos 2 onzas) y seis cajitas de oro (197 castellanos de peso). A eso se añadían los entre 50 y 70 marcos que pesaban la imagen de la Virgen y su marco.

95 ATHA, F. Samaniego, Caja 39, N. 10. Carta de Pedro Sáenz de Santa María a Martín Sáenz de Tejada. Cádiz, 25 de noviembre de 1758. Sobre la estancia de Ensenada en el Puerto de Santa María véase Abad León: El Marqués de la Ensenada, II, págs. 231 y ss. 


\section{Dinero del virrey enviado a España}

Utilizando las conexiones anteriormente mencionadas, está documentado el envío a Cádiz por parte del conde de Superunda de un total de 490.500 pesos fuertes — 9.810.000 reales de vellón— en los últimos seis años de su gobierno en el Perú. ${ }^{96}$

La primera noticia de envío de una partida de plata del virrey de forma encubierta es de 1750. En esta ocasión irá a nombre de Martín de Celayeta, quien remitió a Juan Agustín de Uztáriz, en los navíos Castilla y Europa, 80.000 pesos que en realidad eran de Manso de Velasco; a su vez el mayordomo del virrey dio instrucciones concretas a Uztáriz acerca de lo que se debía hacer con ese dinero. ${ }^{97} \mathrm{El}$ éxito de esta remesa y la habitual relación comercial entre Celayeta y Uztáriz propiciaron nuevos envíos por esa vía.

Así, en febrero de 1752, Juan Bautista de Casabona se encargaba de nuevo de gestionar el envío de otros 20.000 pesos en el navío Nuestra Señora del Pilar "en nombre del amigo Sr. D. Martín de Celayeta", a Juan Agustín de Uztáriz "en cuenta del consabido interesado. ${ }^{98}$ A finales de ese mismo año Martín de Celayeta embarcaba en el navío San Juan Baptista, San Antonio de Padua y Las Ánimas, alias El Toscano, "de su cuenta y riesgo", otros 133.500 pesos dirigidos a Juan Agustín de Uztáriz. En la parte de atrás del impreso de embarque el propio Martín de Celayeta declaraba que ese dinero pertenecía al conde de Superunda. ${ }^{99}$ Dos años más tarde, en

96 Aunque siempre se detalla el tipo de moneda, normalmente doblones de cordoncillo de plata acuñados en Lima, sólo en algunos casos se especifica que son pesos fuertes. Esto último ha llevado a considerar que en todos los casos se trataba de pesos fuertes.

97 ATHA, F. Samaniego, Caja 39, N. 19. Carta de Juan Agustín de Uztáriz a Juan Bautista de Casabona sobre asuntos de embarques. Cádiz, 4 de noviembre de 1751. ATHA, F. Samaniego, Caja 39, N. 26. Carta de Juan Agustín de Uztáriz a Juan Bautista de Casabona sobre asuntos de embarques. Cádiz, 6 de mayo de 1752.

98 ATHA, F. Samaniego, Caja 39, N. 20. Cartas de Juan Bautista de Casabona a Juan Agustín de Uztáriz. Lima, 5 de febrero de 1752 y 10 de marzo de 1752.

99 ATHA, F. Samaniego, Caja 39, N. 05. Conocimiento de embarque hecho por Estevan Joséph de Peña, vecino de Cádiz, maestre de El Toscano. Lima, 22 de diciembre de 1752. Declaración de Martín de Celayeta por la que consta que el dinero embarcado a su nombre en El Toscano es del conde de Superunda. La fórmula de la declaración, que se repite en posteriores embarques al pie de la letra, es: "Declaro yo D. Martín de Celayeta, del orden de Santiago, por suficiente declaración como si fuere hecha ante juez competente, que los 133.500 pesos contenidos en el conocimiento de la vuelta son, tocan y pertenecen al Excmo. Sr. Conde de Superunda, virrey de estos reynos y que en ellos no tengo más intereses ni dominio que el de haver prestado mi nombre. Y para que así conste lo firmé en Lima el 22 de diciembre 1752. Fdo. Martín de Celayeta". 
diciembre de 1754, siguiendo exactamente el mismo procedimiento, e incluyendo declaraciones idénticas, el comerciante vasco remitió, como siempre a Juan Agustín de Uztáriz, 53.000 pesos en el Príncipe Gustavo ${ }^{100}$ y otros 54.000 en la Amable María, que partieron en esas fechas del Callao. ${ }^{101}$

Es en 1757 cuando empieza a organizar los envíos Martín Sáenz de Tejada y cuando entra en esta red su paisano Pedro Sáenz de Santa María, como intermediario en Cádiz. La otra novedad es que Martín de Celayeta pasa a ser sustituido por Juan Francisco Micheo, quien dice enviar las remesas "por quenta y riesgo" de su primo, Juan Agustín de Uztáriz. En febrero de ese año Juan Francisco remitió de esta forma un total de 50.000 pesos del conde de Superunda, que iban junto con otro dinero de los Uztáriz y se embarcaron en dos partidas de 25.000 en los navíos Nuestra Señora del Pilar ${ }^{102}$ y Nuestra Señora del Carmen. ${ }^{103}$ Aunque el destinatario fuera, como siempre, Uztáriz, se advierte al comerciante navarro que debe tener las cantidades a disposición de Pedro Sáenz de Santa María, para lo que indique el virrey. ${ }^{104} \mathrm{El}$ comerciante riojano escribe desde Cádiz en octubre del mismo año comunicando que han llegado "con felicidad" los mencionados navíos y los 50.000 pesos del conde de Superunda, "a entregar a su correspondiente de V.m. y a mi amigo Juan Agustín de Uztáriz", a quien se los pediría si se lo comunicaba el virrey. Empieza ahora también a apa-

100 ATHA, F. Samaniego, Caja 39, N. 05. Conocimiento de embarque hecho por Sebastián de Urrecha, vecino de Cádiz, maestre del Nuestra Señora de Begoña y San José, alias Príncipe Gustavo. Lima, 5 de diciembre de 1754; Declaración de Martín de Celayeta por la que consta que el dinero embarcado a su nombre en el Príncipe Gustavo es del conde de Superunda. Lima, 7 de diciembre de 1754.

101 ATHA, F. Samaniego, Caja 39, N. 05. Conocimiento de embarque hecho por Phelipe de Luxán, vecino de Cádiz, maestre del Nuestra Señora del Rocío, alias la Amable María. Lima, 5 de diciembre de 1754; Declaración de Martín de Celayeta por la que consta que el dinero embarcado a su nombre en la Amable María es del conde de Superunda. Lima, 7 de diciembre de 1754.

102 ATHA, F. Samaniego, Caja 39, N. 13. Conocimiento de embarque hecho por Manuel Prudencio de Moldiebro, vecino de Cádiz, maestre del Nuestra Señora del Pilar y Señor San Joséph. Lima, 5 febrero de 1757; Declaración de Juan Francisco Micheo Uztáriz por la que consta que del dinero embarcado a su nombre en el Nuestra Señora del Pilar, 25.000 pesos son del conde de Superunda y 20.000 de Juan Agustín de Uztáriz. Lima, 5 de febrero de 1757.

103 ATHA, F. Samaniego, Caja 39, N. 13. Conocimiento de embarque hecho por Joséph de Belzunza y Ursúa, maestre del Nuestra Señora del Carmen, alias La Galga. Lima, 7 de febrero de 1757; Declaración de Juan Francisco Micheo Uztáriz por la que consta que del dinero embarcado a su nombre en el Nuestra Señora del Carmen, 25.000 pesos son del conde de Superunda y 20.000 de Juan Agustín de Uztáriz. Lima, 7 de febrero de 1757.

104 ATHA, F. Samaniego, Caja 39, N. 13. Carta de Martín Sáenz de Tejada a Juan Agustín de Uztáriz y Compa .. Lima, 8 de enero de 1757; Carta de Martín Sáenz de Tejada a Pedro Sáenz de Santa María. Lima, 31 de enero de 1757. 
recer en la documentación como destinataria segunda la firma Uztáriz y Compañía. ${ }^{105}$

Al año siguiente se envía una nueva remesa de 25.000 pesos en el San Bruno, siguiendo idéntico mecanismo. Detrás del embarque - hecho a nombre de Juan Francisco de Micheo Uztáriz y dirigido a la firma Uztáriz- está Martín Sáenz de Tejada, ${ }^{106}$ quien oficialmente informa a los gaditanos que ha pasado a sustituir a Casabona en los asuntos de embarques, por haber partido éste a ocupar la plaza de corregidor de Guamalíes; comunica también el pago de los fletes en la salida y pide a Uztáriz que recoja el dinero y lo guarde mientras no se lo pida Pedro Saénz de Santa María, ${ }^{107}$ para quien además iba en este navío el cajón con los regalos de Superunda que se mencionaron anteriormente. ${ }^{108}$ Será de nuevo éste quien informe de la puntual llegada de la nueva partida de plata y del cumplimiento de las instrucciones dadas. ${ }^{109}$ En esas mismas fechas partieron con igual destino otros 25.000 pesos en el navío San Martín, que tuvo problemas técnicos durante el viaje, por lo que se transbordaron a El Príncipe. ${ }^{110}$

La última partida saldría de Lima pocos meses antes de abandonar José Antonio Manso de Velasco el virreinato peruano para emprender el regreso a España por Panamá. Así se lo comunicaba Sáenz de Tejada a Juan Agustín de Uztáriz al tiempo que le informaba que, ante la inminente llegada de su sucesor, el conde había ordenado mandar a Cádiz nueve cajones numerados, ocho con plata labrada y el último con una piedra de plata (de 180 libras de peso), que viajarían en los navíos Nuestra Señora del Rosario

105 ATHA, F. Samaniego, Caja 39, N. 08. Carta de Pedro Sáenz de Santa María a Juan Bautista Casabona. Cádiz, 21 de octubre de 1757.

106 ATHA, F. Samaniego, Caja 39, N. 09. Recibo firmado por Juan Francisco de Micheo y Uztáriz en el que dice que ha recibido de Martín Sáenz de Tejada los 1.806 pesos y 4 reales que por su orden pagó al maestre del navío San Bruno en concepto de fletes, avería, conducción al Callao, registro y certificación. Lima, 30 de marzo de 1758.

107 ATHA, F. Samaniego, Caja 39, N. 09. Carta de Martín Sáenz de Tejada a Juan Agustín de Uztáriz y Cía. Lima, 6 de abril de 1758. Carta de Martín Sáenz de Tejada a Pedro Sáenz de Santa María. Lima, 6 de abril de 1758.

108 ATHA, F. Samaniego, Caja 39, N. 09. Conocimiento de embarque hecho por Antonio de Larrea, vecino de Cádiz, maestre del navío San Bruno. Lima, 30 de marzo de 1758; Declaración de Juan Francisco Micheo Uztáriz por la que consta que el dinero embarcado a su nombre en el San Bruno, pertenece al conde de Superunda. Lima, 30 de marzo de 1758.

En carta aparte, escrita el mismo día, Martín le expresa la gratitud del virrey. ATHA, F. Samaniego, Caja 39, N. 09. Carta de Martín Sáenz de Tejada a Pedro Sáenz de Santa María. Lima, 6 de abril de 1758.

109 ATHA, F. Samaniego, Caja 39, N. 10. Carta de Pedro Sáenz de Santa María a Martín Sáenz de Tejada. Cádiz, 25 de noviembre de 1758.

110 ATHA, F. Samaniego, Caja 39, N. 11. Carta de Martín Sáenz de Tejada a Juan Agustín de Uztáriz. Lima, 25 de febrero de 1761. 
y San Juan Bautista, junto con un cajón lleno de "bálsamos" y "dos zurrones de Calaguala". ${ }^{111}$ A este equipaje se añadía una nueva partida de dinero de 50.000 pesos, divididos también entre ambos navíos. En esta ocasión todo iba a nombre del conde de Superunda y dirigido al presidente de la Casa de la Contratación, Esteban José de Abarzua, con la confianza de que ni el dinero ni la plata labrada pagarían derechos pues el primero iba "como parte de los sueldos que el rey le tiene señalados" y lo segundo "como parte de su vajilla". Martín Sáenz de Tejada explicaba a Juan Agustín de Uztáriz que el virrey quería que guardase el equipaje, mientras determinaba qué destino darle y que custodiara el dinero hasta que se lo pidiera, de su parte, Pedro Sáenz de Santa María. ${ }^{12}$ Lamentablemente no hemos podido comprobar si finalmente se cobraron los derechos reales de este equipaje a su llegada a Cádiz. En cualquier caso, incluyendo esta última cantidad de dinero, la suma total de plata enviada por el virrey durante su gobierno ascendía, según se anunció, a 490.500 pesos fuertes, lo que equivaldría a 9.810 .000 millones de reales de vellón.

\section{Conclusiones}

¿Cómo consiguió el virrey reunir semejante cantidad de dinero? Si se tiene en cuenta que su sueldo eran 30.000 ducados de plata anuales, ${ }^{113}$ es decir, 622.941 reales de vellón al año aproximadamente, a los que se añadían a veces ciertas "ayudas de costa", se puede deducir que el monto total

111 En ambos casos se trataba de remedios curativos propios de la zona. La Calaguala es una planta medicinal propia del altiplano andino que ya menciona Antonio de Ulloa: Viaje al reino del Perú (1748), Andrés Saumell ed., Historia 16, Madrid, 1990, pág. I, 539: "La mas particular virtud de esta planta es la de desvanecer y evacuar toda suerte de apostemas interiores y exteriores, para lo qual es tanta su eficacia y actividad que en tiempo muy corto y con gran facilidad las deshace y destruye dexando al paciente libre de su peligro. El modo de darla es en conocimiento de agua, poniendo corta cantidad ó machacada y puesta en infusion..."

112 ATHA, F. Samaniego, Caja 39, N. 11. Conocimiento de embarque hecho por Balthazar de Arrillaga, maestre del Nuestra Señora del Rosario, alias Galera Esperanza. Lima, 7 de febrero de 1761; Conocimiento de embarque hecho por Joséph Joachin de Sos, maestre del San Juan Bautista, alias El Toscano. Lima, 6 de febrero de 1761; "Razón de la plata labrada con expresión de sus piezas que coprehenden nueve cajones precintados que remite D. Martín Sáenz de Tejada por cuenta y riesgo del Excmo. Sr. Conde de Superunda los quales van en los Navíos la Galera Esperanza y el San Juan Bautista".

113 AGI, Lima 415. Informe de Miguel de Villanueva al conde de Montijo. Madrid, 16 de marzo de 1739. En este informe se hacía constar que en 1725 esta cantidad se le aumentó al virrey Armendáriz en 20.000 pesos de "ayuda de costa", que se dieron igualmente a Villagarcía y Santo Buono, quien recibió una cantidad aún mayor. 
de reales de vellón ingresados en concepto de sueldo por Superunda pudo haber ascendido a casi 10.000.000 reales de vellón. De entrada, la cifra es importante, pero cabe cuestionarse hasta qué punto era posible ahorrar ese dinero. Para ello habría que tener en cuenta cuáles eran los gastos anuales del virrey en el mantenimiento de su casa y familia. Sin embargo, el análisis de estas cuentas "domésticas" se abordará en un estudio posterior por lo que, de momento, únicamente podemos llegar a conclusiones parciales: se envió la cantidad de plata mencionada que, en principio, pudo ser ahorrada del sueldo percibido; sin embargo, todo parece indicar que hubo otras fuentes de ingresos.

Igualmente requerirá una investigación aparte el análisis del destino que se dio a este dinero en España. Es sabido que el 22 de febrero de 1752 Superunda dio un poder notarial en Lima, a favor del marqués de la Ensenada, para que fundara un mayorazgo cuyo beneficiario fuera su sobrino Diego Antonio. Tan sólo dos meses antes de su caída, en mayo de 1754, el marqués llevó a término este encargo y fundó un mayorazgo por valor de 5.170.050 reales de vellón. Evidentemente ese fue el destino de una parte importante del dinero. ${ }^{114}$ Sin embargo, conviene señalar que en esas fechas el virrey había enviado a su protector un total de 233.500 pesos fuertes - no se incluye lo que llegaría en la Amable María y el Príncipe Gustavo - es decir, unos 4.670.000 millones de reales de vellón. Es por lo tanto probable que se pidiera un préstamo para fundar el mayorazgo. Se trata de una hipótesis por demostrar, aunque cabría apuntar hacia la persona de Pedro Sáenz de Santa María —instalado ya en Cádiz desde 1751por la reiterada gratitud que Superunda le manifiesta. Está claro que el primero había hecho algún favor al virrey pero, de momento, no se puede precisar si fue éste. Además, aún dando por válida la hipótesis de la inversión de este dinero directamente en el mayorazgo, todavía quedaría pendiente de resolver qué se hizo con el resto del dinero, el que continuó llegando del Perú desde enero de 1755.

Sin duda, el acceso a una documentación privada, ha permitido constatar una práctica habitual: el envío ilegal de sumas de dinero personal a la metrópoli por parte de altos funcionarios indianos. Pero tal vez lo más interesante ha sido poder desentrañar el mecanismo que se utilizaba para remi-

114 ATHA, F. Samaniego, Caja 28, N. 14 y Caja 39, N. 32. Fundación de un mayorazgo por Zenón de Somodevilla, Marqués de la Ensenada, en nombre y virtud del poder que tiene de José Antonio Manso de Velasco, a favor de su sobrino Diego Antonio Manso de Velasco y Crespo. Aranjuez, Madrid, 26 de mayo de 1754. 
tir esos caudales. No siempre las fuentes contienen una información tan rica. En cualquier caso, con este trabajo se ha pretendido aproximarse desde una nueva perspectiva al funcionamiento de la administración indiana y demostrar, en cierta manera, que detrás de una persona destacada había otras, vinculadas con el territorio americano y con el peninsular, que eran los verdaderos agentes de este tipo de operaciones. 